\title{
Collagen-derived $N$-acetylated proline-glycine-proline upregulates the expression of pro-inflammatory cytokines and extracellular matrix proteases in nucleus pulposus cells via the NF-кB and MAPK signaling pathways
}

\author{
CHENCHENG FENG ${ }^{*}$, JINYUE HE*, YANG ZHANG, MINGHONG LAN, MINGHUI YANG, \\ HUAN LIU, BO HUANG, YONG PAN and YUE ZHOU
}

Department of Orthopaedics, Xinqiao Hospital, The Third Military Medical University, Chongqing 400037, P.R. China

Received December 13, 2016; Accepted May 18, 2017

DOI: 10.3892/ijmm.2017.3005

\begin{abstract}
N$-acetylated proline-glycine-proline ( $N$-Ac-PGP) is a chemokine involved in inflammatory diseases and is found to accumulate in degenerative discs. $N$-Ac-PGP has been demonstrated to have a pro-inflammatory effect on human cartilage endplate stem cells. However, the effect of $N$-Ac-PGP on human intervertebral disc cells, especially nucleus pulposus (NP) cells, remains unknown. The purpose of this study was to investigate the effect of $N$-Ac-PGP on the expression of pro-inflammatory factors and extracellular matrix (ECM) proteases in NP cells and the molecular mechanism underlying this effect. Therefore, Milliplex assays were used to detect the levels of various inflammatory cytokines in conditioned culture medium of NP cells treated with $N$-Ac-PGP, including interleukin-1 $\beta$ (IL-1 $\beta$ ),
\end{abstract}

Correspondence to: Professor Yong Pan or Professor Yue Zhou, Department of Orthopaedics, Xinqiao Hospital, The Third Military Medical University, 183 Xinqiao Main Street, Shapingba, Chongqing 400037, P.R. China

E-mail: bravepan@163.com

E-mail: happyzhou@vip.163.com

${ }^{*}$ Co-first authors

Abbreviations: IVD, intervertebral disc; IDD, intervertebral disc degeneration; NP, nucleus pulposus; $\mathrm{AF}$, annulus fibrosus; $N$-Ac-PGP, $N$-acetylated proline-glycine-proline; ECM, extracellular matrix; LBP, low back pain; MMP, matrix metalloproteinase; PE, prolyl endopeptidase; CESCs, cartilage endplate stem cells; CEP, cartilage endplate; NF- $\kappa \mathrm{B}$, nuclear factor- $\kappa \mathrm{B}$; MAPK, mitogen-activated protein kinase; ADAMTS, a disintegrin and metalloproteinase with thrombospondin motifs; PBS, phosphate-buffered saline; IL, interleukin; TNF, tumor necrosis factor; CCL, C-C motif ligand; CXCL10, C-X-C motif chemokine ligand 10; RPL, relative phosphorylation level

Key words: intervertebral disc degeneration, $\mathrm{N}$-acetylated prolineglycine-proline, pro-inflammatory phenotype, matrix catabolic phenotype, nuclear factor- $\kappa \mathrm{B}$, mitogen-activated protein kinase
IL-6, IL-17, tumor necrosis factor- $\alpha$ (TNF- $\alpha)$ and C-C motif ligand 2 (CCL2). RT-qPCR was also used to determine the expression of pro-inflammatory cytokines and ECM proteases in the NP cells treated with $N$-Ac-PGP. Moreover, the role of nuclear factor- $\kappa \mathrm{B}(\mathrm{NF}-\kappa \mathrm{B})$ and mitogen-activated protein kinase (MAPK) signaling pathways in mediating the effect of $N$-Ac-PGP on the phenotype of NP cells was investigated using specific signaling inhibitors. Milliplex assays showed that NP cells treated with $N$-Ac-PGP $(10$ and $100 \mu \mathrm{g} / \mathrm{ml})$ secreted higher levels of IL-1 $\beta$, IL-6, IL-17, TNF- $\alpha$ and CCL2 compared with the control. RT-qPCR assays showed that NP cells treated with $N$-Ac-PGP $(100 \mu \mathrm{g} / \mathrm{ml})$ had markedly upregulated expression of matrix metalloproteinase 3 (MMP3), MMP13, a disintegrin and metalloproteinase with thrombospondin motif 4 (ADAMTS4), ADAMTS5, IL-6, CCL-2, CCL-5 and C-X-C motif chemokine ligand 10 (CXCL10). Moreover, $N$-Ac-PGP was shown to activate the MAPK and $\mathrm{NF}-\kappa \mathrm{B}$ signaling pathways in NP cells. MAPK and NF- $\kappa \mathrm{B}$ signaling inhibitors suppressed the upregulation of proteases and pro-inflammatory cytokines in NP cells treated with $N$-Ac-PGP. In conclusion, $N$-Ac-PGP induces the expression of pro-inflammatory cytokines and matrix catabolic enzymes in NP cells via the NF- $\mathrm{NB}$ and MAPK signaling pathways. $N$-Ac-PGP is a novel therapeutic target for intervertebral disc degeneration.

\section{Introduction}

Low back pain (LBP) is a major threat to the health of middle-aged and elderly individuals, among whom nearly one-third require surgery. LBP causes a heavy socio-economical burden. Intervertebral disc degeneration (IDD) is widely recognized as a main contributor to LBP. The etiological factors of IDD include aging, smoking, abnormal mechanical loading, occupational exposure and trauma (1-6). IDD is characterized by decreased disc height, nucleus pulposus (NP) dehydration, annulus fibrosus (AF) tear, immune cell infiltration, neovascularization and neuronal ingrowth $(7,8)$. Therapeutic measures based on preventing and delaying the initiation and progression of IDD are considered to be effective measures for LBP treatment. 
The pro-inflammatory and catabolic phenotype of disc cells has been identified in degenerative discs. Extracellular matrix (ECM) catabolic proteases are potently associated with the structural failure of discs. Pro-inflammatory cytokines suppress the matrix synthesis of disc cells and upregulate the expression of matrix proteases in disc cells, leading to an imbalance between matrix anabolism and catabolism in IVDs. Moreover, pro-inflammatory cytokines are able to induce the senescence, apoptosis and autophagy of disc cells $(9,10)$. Therefore, the pro-inflammatory and catabolic phenotype of disc cells is detrimental to the structural and functional homeostasis of discs. Noticeably, the viability and function of disc cells are regulated by the microenvironment of discs. The microenvironment of degenerative IVDs is characterized by low $\mathrm{pH}$, high osmotic pressure, hypoxia and low nutrition. The harsh microenvironment of degenerative discs disrupts the homeostasis of disc cells, which plays a crucial role in the pathogenesis of IDD (11). However, the regulatory effect of the microenvironment on the pro-inflammatory and catabolic phenotype of disc cells has not been elucidated.

$N$-acetylated proline-glycine-proline $(N$-Ac-PGP) is a tripeptide generated from collagens degraded by matrix metalloproteinase 8 (MMP8), MMP9 and prolyl endopeptidase (PE) (12). Previous studies have reported the wide role of $\mathrm{N}$-Ac-PGP in neutrophilic inflammatory diseases, such as chronic obstructive pulmonary disease and inflammatory bowel disease $(13,14)$. Recently, we identified the presence of $N$-Ac-PGP in human NP tissues. The level of $N$-Ac-PGP in NP tissues is positively correlated with the grade of IDD, suggesting the involvement of $N$-Ac-PGP in the pathogenesis of IDD. Moreover, $N$-Ac-PGP promotes the migration of cartilage endplate stem cells (CESCs) and induces the differentiation of CESCs toward a pro-inflammatory and catabolic phenotype via CXCR1/2. Thus, we conclude that $N$-Ac-PGP is a pro-inflammatory and catabolic matrikine in the microenvironment of IVDs (15). Nevertheless, the effect of $N$-Ac-PGP on human functional disc cells and the molecular mechanism underlying this effect remain unknown.

In this study, the Milliplex MAP assay (Millipore, Billerica, MA, USA) was used to measure the level of pro-inflammatory cytokines in conditioned culture medium of human NP cells treated with $N$-Ac-PGP. We also analyzed the expression of pro-inflammatory cytokines and matrix catabolic proteases in NP cells using reverse transcription-quantitative PCR (RT-qPCR). Lastly, we investigated the activation of the nuclear factor- $\kappa \mathrm{B}$ $(\mathrm{NF}-\kappa \mathrm{B})$ and mitogen-activated protein kinase (MAPK) signaling pathways in NP cells treated with $N$-Ac-PGP. The role of the $\mathrm{NF}-\kappa \mathrm{B}$ and MAPK signaling pathways in mediating the effect of $N$-Ac-PGP on the phenotype of NP cells was investigated using specific signaling inhibitors. Our study, for the first time, elucidated the effect of $N$-Ac-PGP on the catabolic and pro-inflammatory signaling of human NP cells via the NF- $\kappa$ B and MAPK pathways, further revealing the roles of $N$-Ac-PGP in the pathogenesis of IDD. The present study provides a novel insight into the mechanism underlying the establishment and progression of IDD.

\section{Materials and methods}

Ethics statement. The present study was performed complying with the ethical standards set forth by the Declaration of
Helsinki, and was approved by the Ethics Committee of Xinqiao Hospital (Chonqing, China).

Reagents and antibodies. $N$-Ac-PGP was provided by Sigma-Aldrich (St. Louis, MO, USA). $N$-Ac-PGP was diluted with phosphate-buffered saline (PBS; $1 \mathrm{mg} / \mathrm{ml})$. The rabbit monoclonal anti-human p38 (no. 9212), phospho-p38 (p-p38; no. 9211), JNK (no. 9252), p-JNK (no. 9251), ERK (no. 9102) and p-ERK (no. 9101) antibodies were all obtained from Cell Signaling Technology, Inc. (Danvers, MA, USA). The mouse monoclonal anti-human GAPDH (sc-47724) antibody was provided by Santa Cruz Biotechnology, Inc. (Santa Cruz, CA, USA). The rabbit polyclonal anti-human p65 antibody (ab16502) and the rabbit monoclonal anti-human p-p65 antibody (ab76302) were both purchased from Abcam (Cambridge, MA, USA). The goat polyclonal anti-mouse $\operatorname{IgG}(\mathrm{H}+\mathrm{L})$ horseradish peroxidase (HRP)-conjugated secondary antibody (ZB2305) and the goat anti-rabbit IgG $(\mathrm{H}+\mathrm{L}) \mathrm{HRP}$-conjugated secondary antibody (ZB2301) were both purchased from ZSGB-BIO (Beijing, China). The p38 (SB202190, SB), JNK (SP600125, SP) and ERK (U0126, U) signaling inhibitors were provided by MedChem Express (Princeton, NJ, USA). The NF- $\kappa \mathrm{B}$ inhibitor (PDTC) was purchased from Beyotime Institute of Biotechnology (Shanghai, China).

NP cell culture. Human NP tissues were collected from 8 patients undergoing lumbar discectomy and a fusion procedure in Xinqiao Hospital (Chongqing, China) (Table I). Pre-operative MRI was performed to evaluate the Pfirrmann grade of the intervertebral discs (IVDs) (16). IVD specimens were preserved in sterile saline solution once dissected from the human body. NP tissues, a gel-like tissue, were carefully isolated from IVD specimens and minced into thin tissue blocks $\left(1 \mathrm{~mm}^{3}\right)$. After washing with PBS three times, NP tissues were incubated with $0.2 \%$ type II collagenase (Sigma-Aldrich) in Dulbecco's modified Eagle's medium (DMEM)/F-12 medium (Invitrogen Life Technologies, Carlsbad, CA, USA) at $37^{\circ} \mathrm{C}$ for $12 \mathrm{~h}$. Next, the suspension was collected and centrifuged at 1,200 rpm for $6 \mathrm{~min}$. The isolated NP cells were cultured in DMEM/F-12 medium containing 10\% fetal bovine serum (FBS) and 1\% penicillin/streptomycin (Invitrogen Life Technologies), and grew as a monolayer in $5 \% \mathrm{CO}_{2}$ at $37^{\circ} \mathrm{C}$. The medium was replaced by fresh medium twice a week. When the cells reached about $80 \%$ confluence, they were sub-cultured. NP cells from different patients were pooled at passage 1 and were used at passage 2 or 3 . The marker genes of NP cells used in this study were analyzed by semi-quantitative reverse transcription PCR. Three NP cell-positive gene markers [CA12, KRT19 and CDH2 (17)] and a NP cell-negative gene marker [IBSP (17)] were validated (data not shown).

Milliplex MAP assay. NP cells were trypsinized and seeded into 6-well culture plates (Corning Inc., Corning, NY, USA). They were then treated with various concentrations of $N$-Ac-PGP $(0.1,1,10$ and $100 \mu \mathrm{g} / \mathrm{ml})$ for different durations $\left(1,3,5\right.$ and 7 days) at $37^{\circ} \mathrm{C}$ with $5 \% \mathrm{CO}_{2}$. The conditioned media were harvested for Milliplex MAP Human Cytokine/Chemokine Multiplex Immunoassay (Millipore). The cytokines and chemokines included interleukin-1 $\beta$ (IL-1 $\beta$ ), IL-6, IL-17, C-C motif ligand 2 (CCL2) and tumor necrosis 
Table I. Demographic information of the NP tissue donors.

\begin{tabular}{llcc}
\hline Donors & Sex & Age (years) & $\begin{array}{c}\text { Pfirrmann } \\
\text { grade }\end{array}$ \\
\hline Patient 1 & Male & 43 & II \\
Patient 2 & Male & 36 & II \\
Patient 3 & Male & 48 & III \\
Patient 4 & Male & 52 & III \\
Patient 5 & Male & 57 & III \\
Patient 6 & Female & 42 & II \\
Patient 7 & Female & 41 & III \\
Patient 8 & Female & 37 & II \\
\hline
\end{tabular}

factor- $\alpha$ (TNF- $\alpha$ ). In brief, $25 \mu 1$ standard solution, $25 \mu 1$ mixed beads and $200 \mu \mathrm{l}$ wash water were incubated in one well for $17 \mathrm{~h}$ at $4^{\circ} \mathrm{C}$ and for $2 \mathrm{~h}$ at room temperature. Then, after washing with wash buffer three times, $25 \mu \mathrm{l}$ antibodies was added to each well and incubation was carried out at $25^{\circ} \mathrm{C}$ for $1 \mathrm{~h}$. After adding $25 \mu \mathrm{l}$ of streptavidin-phycoerythrin to each well, the solution was incubated for $1 \mathrm{~h}$ at $25^{\circ} \mathrm{C}$. Lastly, the wells were washed with wash buffer three times and were treated with $150 \mu \mathrm{l}$ of sheath fluid. An automated immunoassay analyzer (Luminex $200^{\mathrm{TM}}$; Millipore) was used to detect the fluorescence intensity of each well. NP cells without any treatment served as the blank control. NP cells treated with PBS served as the negative control. Median fluorescent intensity (MFI) data were analyzed using a 5-parameter logistic or spline-fitting method for calculating cytokine or chemokine concentrations in the conditioned culture media.

Treatment with MAPK and $N F-\kappa B$ signaling inhibitors. To analyze the effect of $N$-Ac-PGP on the phosphorylation of ERK, JNK, p38 and p65, NP cells were treated with $N$-Ac-PGP $(100 \mu \mathrm{g} / \mathrm{ml})$ for $15,30,45$ and $60 \mathrm{~min}$. The activation of these signaling pathways was investigated via western blot assays. In order to determine the role of the MAPK and NF- $\mathrm{\kappa B}$ signaling pathways in mediating the catabolic and pro-inflammatory effect of $N$-Ac-PGP, NP cells were pre-treated with $\mathrm{U}(1 \mu \mathrm{g} / \mathrm{ml})$, SP $(1 \mu \mathrm{g} / \mathrm{ml}), \mathrm{SB}(1 \mu \mathrm{g} / \mathrm{ml})$ and PDTC $(1 \mu \mathrm{g} / \mathrm{ml})$ for $30 \mathrm{~min}$ followed by $N$-Ac-PGP treatment $(100 \mu \mathrm{g} / \mathrm{ml})$ for 3 days. After that, the total RNA of the NP cells was isolated to perform RT-qPCR analysis. NP cells without any treatment served as the control.

$R T-q P C R$. The RNeasy Mini kit (Qiagen, Valencia, CA, USA) was used to extract total RNA of the NP cells. RNA $(1 \mu \mathrm{g})$ was used to perform reverse transcription using the Omniscript Reverse Transcription kit (Qiagen) according to the protocol provided the manufacturer. RT-qPCR was performed using a ViiA7 Real-Time PCR system (Applied Biosystems, Foster City, CA, USA) and the QuantiNova ${ }^{\mathrm{TM}}$ SYBR-Green PCR kit (Qiagen) according to the manufacturer's instructions. The $20 \mu \mathrm{l}$ reaction volume was applied. Reaction parameters were as follows: initial heat activation for $2 \mathrm{~min}$ at $95^{\circ} \mathrm{C}$, followed by 40 cycles of $5 \mathrm{sec}$ at $95^{\circ} \mathrm{C}$ for template denaturation and $34 \mathrm{sec}$ at $60^{\circ} \mathrm{C}$ for annealing and extension. All samples were amplified in triplicate, and the results are
Table II. Primer sequences used in the RT-qPCR analysis.

Genes Primer sequences

\begin{tabular}{ll}
\hline MMP3 & F: CACGGAACCTGTCCCTCCAGAA \\
& R: GCATCCACGCCTGAAGGAAGAG \\
MMP13 & F: CTGGCTGCCTTCCTCTTCTTGA \\
& R: GTCATGGAGCTTGCTGCATTCT \\
ADAMTS4 & F: AAGAGTCCTGCCAGCGGTCAA \\
& R: ATCTGCCACCACCAGTGTCTCC \\
ADAMTS5 & F: TGTCCTGCCAGCGGATGTGT \\
& R: GATGCCGTCACAGCCAGTTCTC \\
IL-6 & F: AGCCAGAGCTGTGCAGATGAGT \\
& R: GGCATTTGTGGTGGGTCAGGG \\
CCL2 & F: ACCAGCAGCAAGTGTCCCAAAG \\
& R: GGGTTTGCTTGTCCAGGTGGTC \\
CCL5 & F: CAGCAGTCGTCCACAGGTCAAG \\
& R: GGCACACACTTGGCGGTTCTT \\
CXCL10 & F: GGAACCTCCAGTCTCAGCACCA \\
& R: GCTGATGCAGGTACAGCGTAC \\
GAPDH & F: CCAGCAAGAGCACAAGAGGAAGAG \\
& R: GGTCTACATGGCAACTGTGAGGAG
\end{tabular}

F, forward; R, reverse; MMP, matrix metalloproteinase; ADAMTS, a disintegrin and metalloproteinase with thrombospondin motif; IL, interleukin; CCL, C-C motif ligand; CXCL10, C-X-C motif chemokine ligand 10 .

presented as a $\mathrm{Ct}$ value, which is the cycle number at which the amplified product is first detected. The expression level of the targeted genes was normalized to that of GAPDH. Relative mRNA expression levels of target genes were calculated using the $2^{-\Delta \Delta \mathrm{Ct}}$ method (18). The primers of the target genes investigated in the present study are listed in Table II.

Western blot analysis. NP cells were lysed with radioimmunoprecipitation assay lysis buffer (Thermo Fisher Scientific, Inc., Waltham, MA, USA) containing proteinase inhibitor on ice for $30 \mathrm{~min}$. A BCA kit (Beyotime Institute of Biotechnology) was used to measure the concentration of the proteins. The proteins were mixed with loading buffer (Invitrogen Life Technologies). Proteins (50 $\mu \mathrm{g}$ ) were separated by $10 \%(w / v)$ sodium dodecyl sulfate-polyacrylamide gel electrophoresis (SDS-PAGE), and were then transferred to polyvinylidene fluoride (PVDF) membranes (Millipore). PVDF membranes were blocked with $5 \%$ non-fat milk in Tris-buffered saline (TBS) for $1 \mathrm{~h}$ at $37^{\circ} \mathrm{C}$ and then were incubated with primary antibodies against GAPDH (1:1,000 dilution), p65 (1:1,000 dilution), p-p65 (1:1,000 dilution), p38 (1:1,000 dilution), p-p38 (1:1,000 dilution), ERK (1:1,000 dilution), p-ERK (1:1,000 dilution), JNK (1:1,000 dilution) and p-JNK (1:100 dilution) overnight at $4^{\circ} \mathrm{C}$. After rinsing with TBS three times, PVDF membranes were incubated with HRP-conjugated secondary antibodies respectively at $37^{\circ} \mathrm{C}$ for $1 \mathrm{~h}$. Lastly, the target proteins were detected 

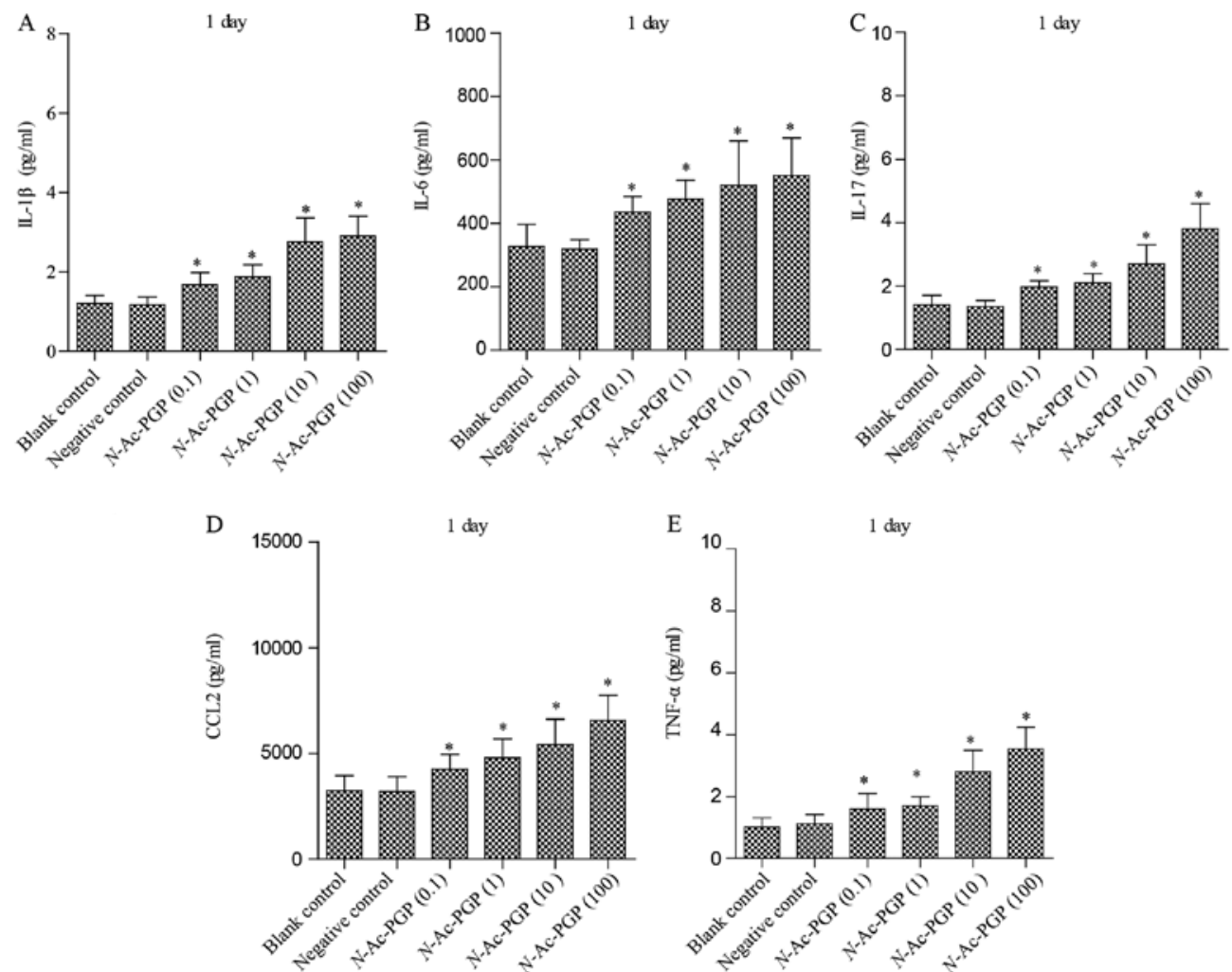

Figure 1. Secretion of pro-inflammatory cytokines by nucleus pulposus (NP) cells treated with $N$-acetylated proline-glycine-proline ( $N$-Ac-PGP) for 1 day. (A-E) The levels of interleukin-1 $\beta$ (IL-1 $\beta$ ), IL-6, IL-17, C-C motif ligand 2 (CCL2) and tumor necrosis factor- $\alpha$ (TNF- $\alpha$ ) in the conditioned culture media of NP cells treated with $N$-Ac-PGP. NP cells without any treatment served as the blank control. NP cells treated with phosphate-buffered saline (PBS) served as the negative control. The results are presented as the mean \pm SEM. ${ }^{*} \mathrm{P}<0.05$ vs. the blank control. $0.1,0.1 \mu \mathrm{g} / \mathrm{ml} ; 1,1 \mu \mathrm{g} / \mathrm{ml} ; 10,10 \mu \mathrm{g} / \mathrm{ml} ; 100,100 \mu \mathrm{g} / \mathrm{ml}$.

using an enhanced chemiluminescence system (Millipore, Bedford, MA, USA) and scanned using an ImagineQuant LAS 4000 (GE Healthcare, Fairfield, CT, USA). The optical density (OD) of the western blot bands was measured using ImageJ software (National Institutes of Health, Bethesda, MD, USA). The phosphorylation level of each protein $=\mathrm{OD}$ of the phospho-protein/OD of total protein. The relative phosphorylation level (RPL) of proteins in each group $=$ the phosphorylation level of proteins in each group/the phosphorylation level of proteins in the control group.

Statistical analysis. All experiments were independently performed at least three times. The data are presented as the mean \pm standard error of the mean (SEM). For multiple comparisons among three or more groups, the one-way analysis of variance (ANOVA) and the least significant difference (LSD) comparison were performed. The data of RT-qPCR were analyzed by Kruskal-Wallis non-parametric analysis and Mann-Whitney $U$ post hoc tests as previously mentioned (19). GraphPad Prism 6 (GraphPad Software, Inc., La Jolla, CA, USA) and SPSS version 22.0 statistical software (International Business Machines Corporation, Armonk, NY, USA) were used to analyze and display the data of this study. $\mathrm{P}<0.05$ was regarded as indicative of statistical significance.

\section{Results}

$N$-Ac-PGP increases the secretion of pro-inflammatory cytokines by NP cells in a dose-dependent manner. The conditioned culture media of NP cells treated with $N$-Ac-PGP $(0.1,1,10$ and $100 \mu \mathrm{g} / \mathrm{ml})$ for various durations $(1,3,5$ and 7 days) were collected to measure the level of pro-inflammatory cytokines secreted by NP cells. As shown in Fig. 1, after treatment with various concentrations of $N$-Ac-PGP for 1 day, increases in the secretion of IL-1 $\beta$, IL-6, IL-17, CCL2 and TNF- $\alpha$ by NP cells were observed regardless of the concentration of $N$-Ac-PGP. With increasing duration of $N$-Ac-PGP treatment, the inductive effect of $N$-Ac-PGP on the secretion of IL-1 $\beta$, IL- 6 , IL-17, CCL2 and TNF- $\alpha$ by NP cells was observed (Figs. 2-4), indicating the potent pro-inflammatory effect of $N$-Ac-PGP on human NP cells. Furthermore, the pro-inflammatory effect of $\mathrm{N}$-Ac-PGP was shown to be dose-dependent. Taking Fig. 2 as an example, the secretion of IL- $1 \beta$ started to increase after $1 \mu \mathrm{g} / \mathrm{ml}$ of $N$-Ac-PGP treatment while there was no significant change in NP cells treated with $0.1 \mu \mathrm{g} / \mathrm{ml}$ of $N$-Ac-PGP. With increasing concentrations of $N$-Ac-PGP (10 and $100 \mu \mathrm{g} /$ $\mathrm{ml}$ ), a higher magnitude of increased IL-1 $\beta$ secretion induced by $N$-Ac-PGP was determined (Fig. 2). Noticeably, the inductive effect of $N$-Ac-PGP on the secretion of IL-6, IL-17, CCL2 and TNF- $\alpha$ by NP cells showed a similar dosedependent trend (Figs. 1-4). Generally speaking, $N$-Ac-PGP at 10 and $100 \mu \mathrm{g} / \mathrm{ml}$ showed a significant pro-inflammatory effect on NP cells. Thus, $N$-Ac-PGP is a potent pro-inflammatory matrikine in the microenvironment of discs.

The temporal pattern of the pro-inflammatory effect of $N$-Ac-PGP on NP cells. As mentioned above, N-Ac-PGP enhanced the secretion of pro-inflammatory cytokines by NP 

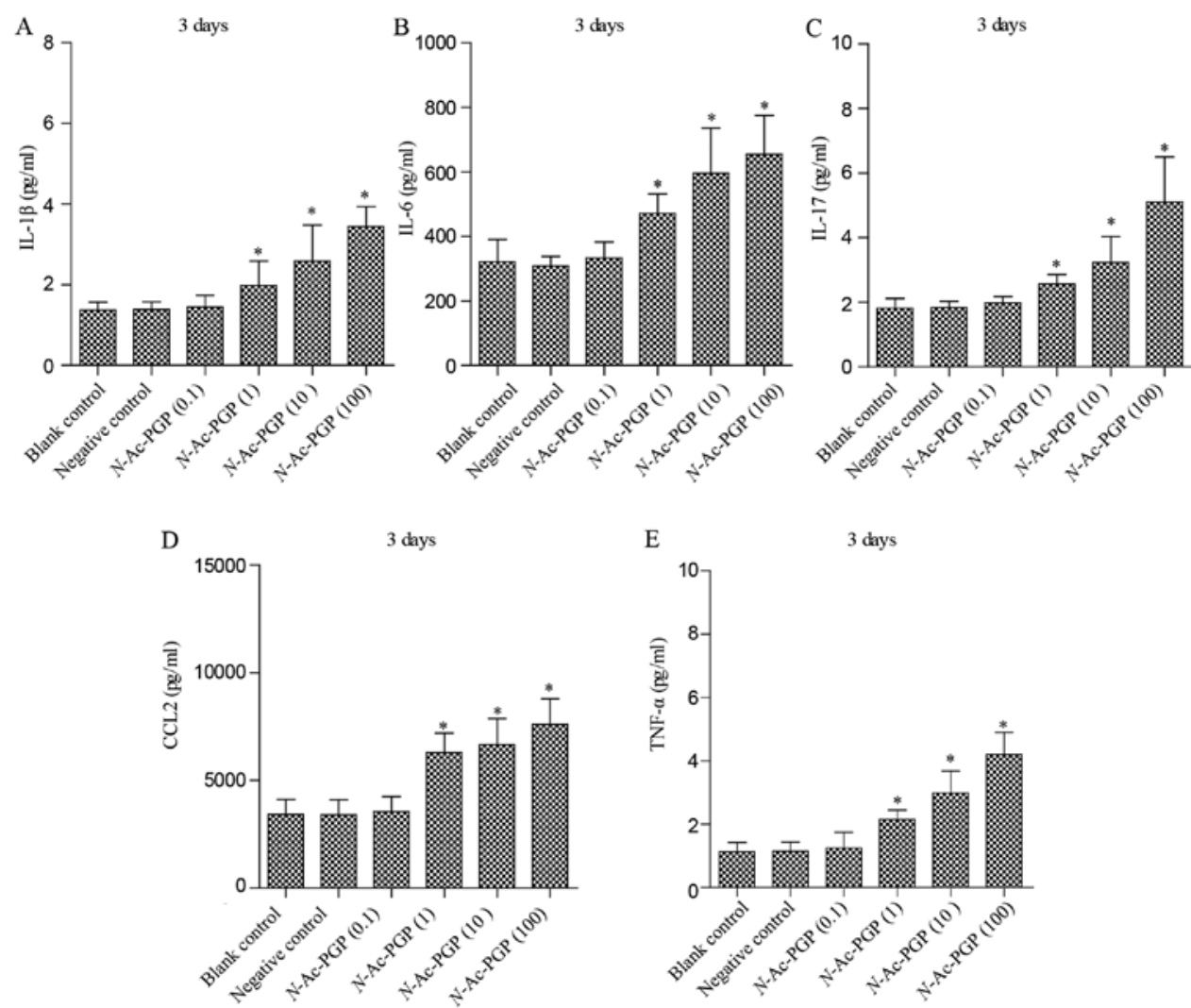

Figure 2. Secretion of pro-inflammatory cytokines by nucleus pulposus (NP) cells treated with $N$-acetylated proline-glycine-proline ( $N$-Ac-PGP) for 3 days (A-E) The level of interleukin-1 $\beta$ (IL-1 $\beta$ ), IL-6, IL-17, C-C motif ligand 2 (CCL2) and tumor necrosis factor- $\alpha$ (TNF- $\alpha$ ) in the conditioned culture media of NP cells treated with $N$-Ac-PGP. NP cells without any treatment served as the blank control. NP cells treated with phosphate-buffered saline (PBS) served as the negative control. The results are presented as the mean \pm SEM. ${ }^{*} \mathrm{P}<0.05$ vs. the blank control. $0.1,0.1 \mu \mathrm{g} / \mathrm{ml} ; 1,1 \mu \mathrm{g} / \mathrm{ml} ; 10,10 \mu \mathrm{g} / \mathrm{ml} ; 100,100 \mu \mathrm{g} / \mathrm{ml}$.
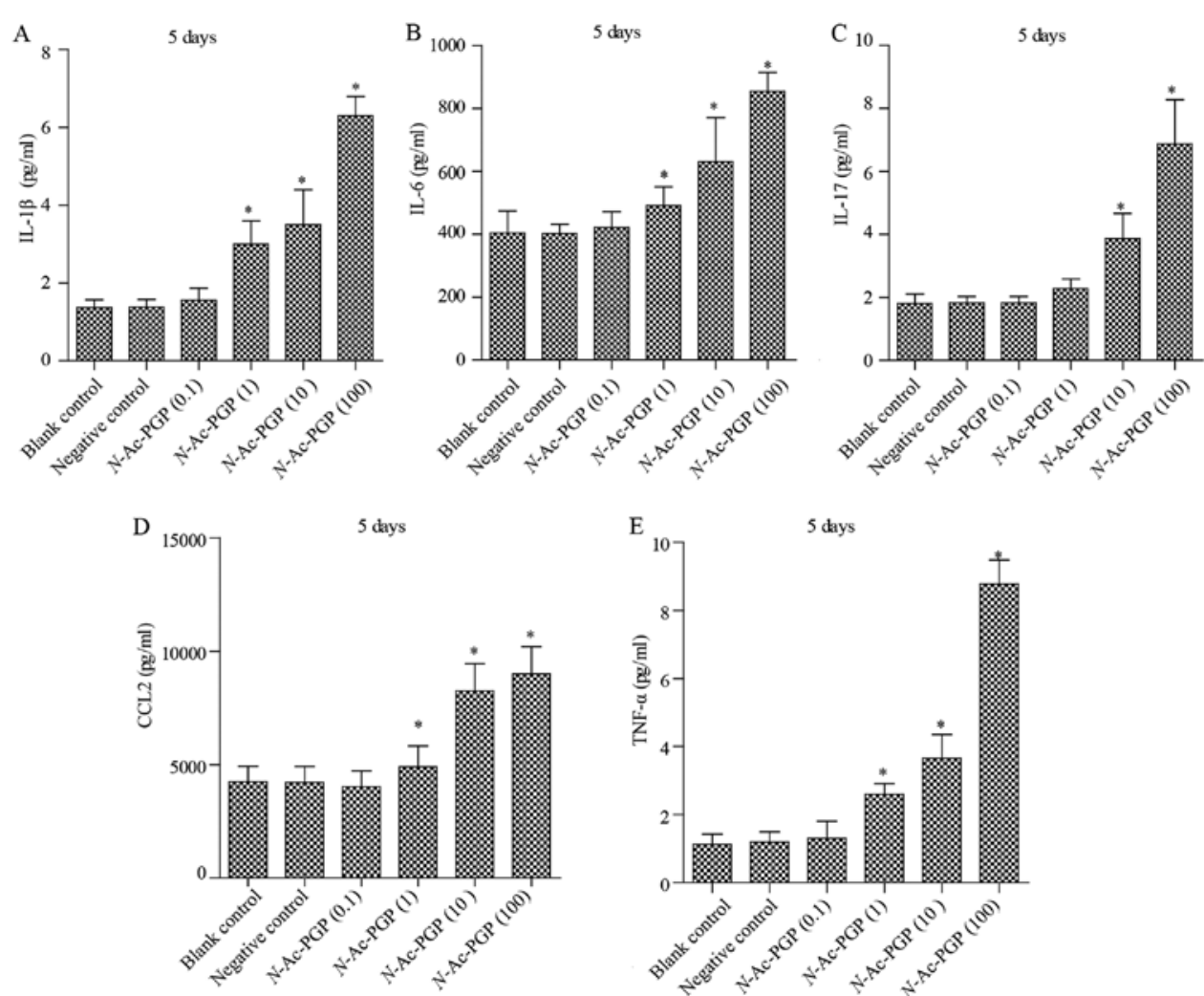

Figure 3. Secretion of pro-inflammatory cytokines by nucleus pulposus (NP) cells treated with $N$-acetylated proline-glycine-proline ( $N$-Ac-PGP) for 5 days (A-E) The level of interleukin-1 $\beta$ (IL-1 $\beta$ ), IL-6, IL-17, C-C motif ligand 2 (CCL2) and tumor necrosis factor- $\alpha$ (TNF- $\alpha$ ) in the conditioned culture media of NP cells treated with $N$-Ac-PGP. NP cells without any treatment served as the blank control. NP cells treated with phosphate-buffered saline (PBS) served as the negative control. The results are presented as the mean \pm SEM. "P<0.05 vs. the blank control. $0.1,0.1 \mu \mathrm{g} / \mathrm{ml} ; 1,1 \mu \mathrm{g} / \mathrm{ml} ; 10,10 \mu \mathrm{g} / \mathrm{ml} ; 100,100 \mu \mathrm{g} / \mathrm{ml}$. 


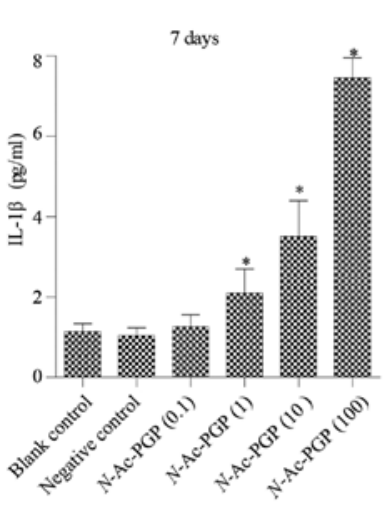

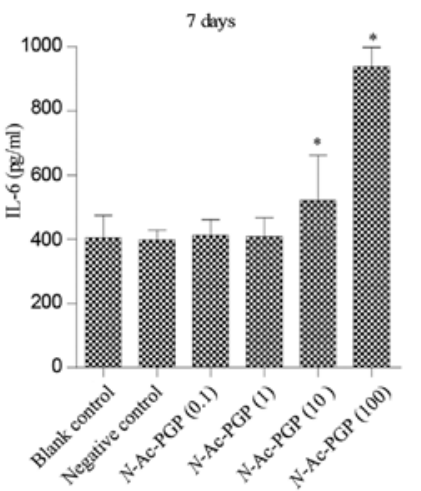

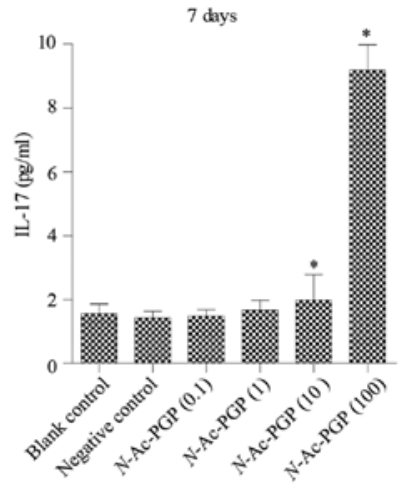

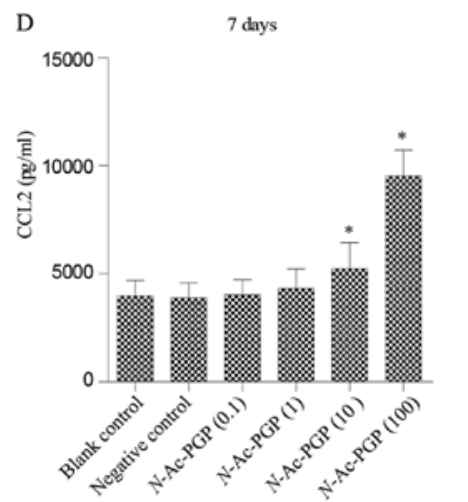

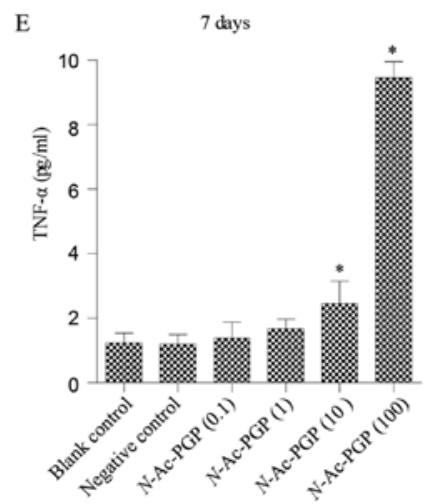

Figure 4. Secretion of pro-inflammatory cytokines by nucleus pulposus (NP) cells treated with $N$-acetylated proline-glycine-proline ( $N$-Ac-PGP) for 7 days. (A-E) The level of interleukin-1 $\beta$ (IL-1 $\beta$ ), IL-6, IL-17, C-C motif ligand 2 (CCL2) and tumor necrosis factor- $\alpha$ (TNF- $\alpha$ ) in the conditioned culture media of NP cells treated with $N$-Ac-PGP. NP cells without any treatment served as the blank control. NP cells treated with phosphate-buffered saline (PBS) served as the negative control. The results are presented as the mean \pm SEM. " $\mathrm{P}<0.05$ vs. the blank control. $0.1,0.1 \mu \mathrm{g} / \mathrm{ml} ; 1,1 \mu \mathrm{g} / \mathrm{ml} ; 10,10 \mu \mathrm{g} / \mathrm{ml} ; 100,100 \mu \mathrm{g} / \mathrm{ml}$.
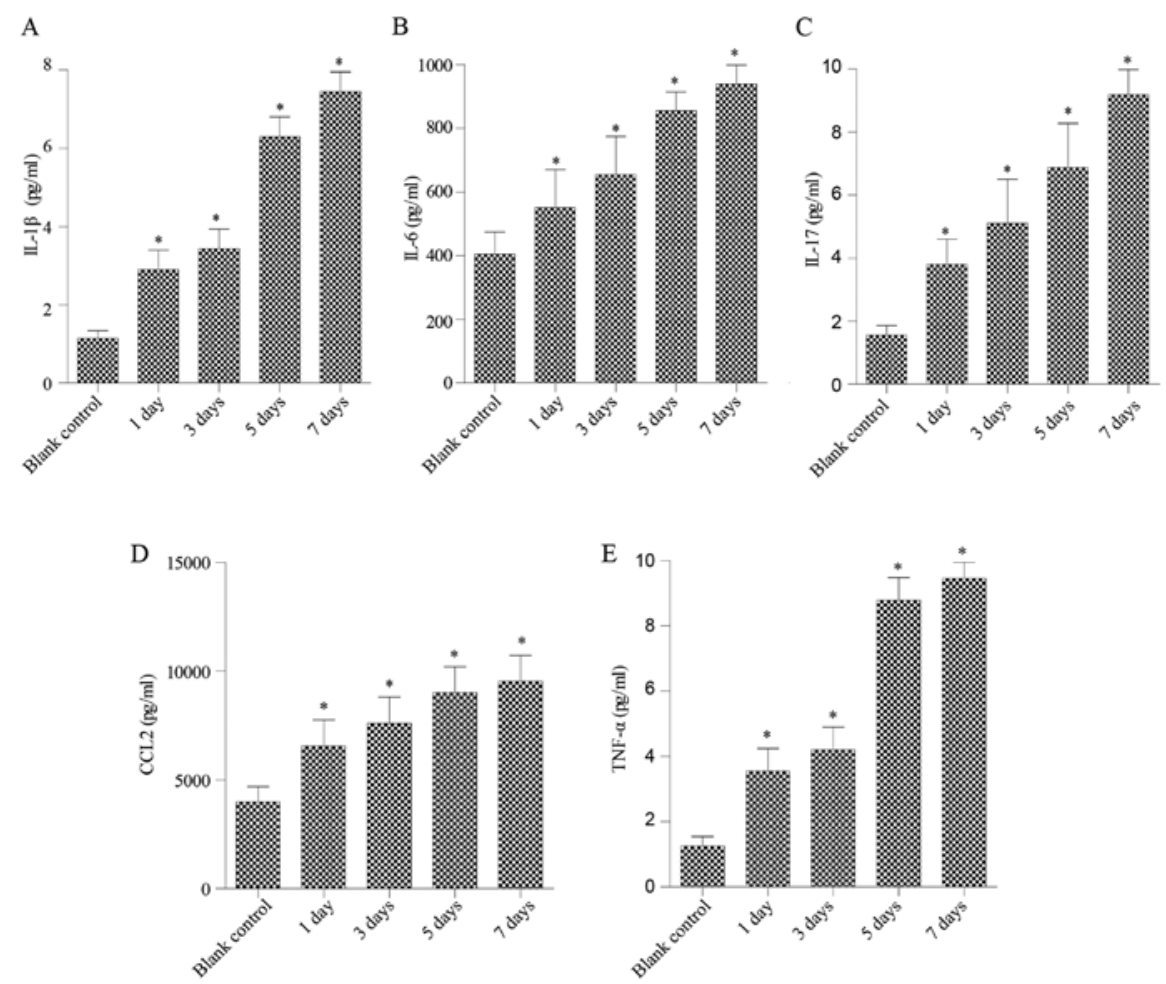

Figure 5. Secretion of pro-inflammatory cytokines by nucleus pulposus (NP) cells treated with $N$-acetylated proline-glycine-proline ( $N$-Ac-PGP, $100 \mu \mathrm{g} / \mathrm{ml})$ for different durations. (A-E) The level of interleukin-1 $\beta$ (IL-1 $\beta$ ), IL-6, IL-17, C-C motif ligand 2 (CCL2) and tumor necrosis factor- $\alpha$ (TNF- $\alpha$ ) in the conditioned culture media of NP cells treated with $N$-Ac-PGP. NP cells without any treatment served as the blank control. The results are presented as the mean \pm SEM. ${ }^{*} \mathrm{P}<0.05$ vs. the blank control. 

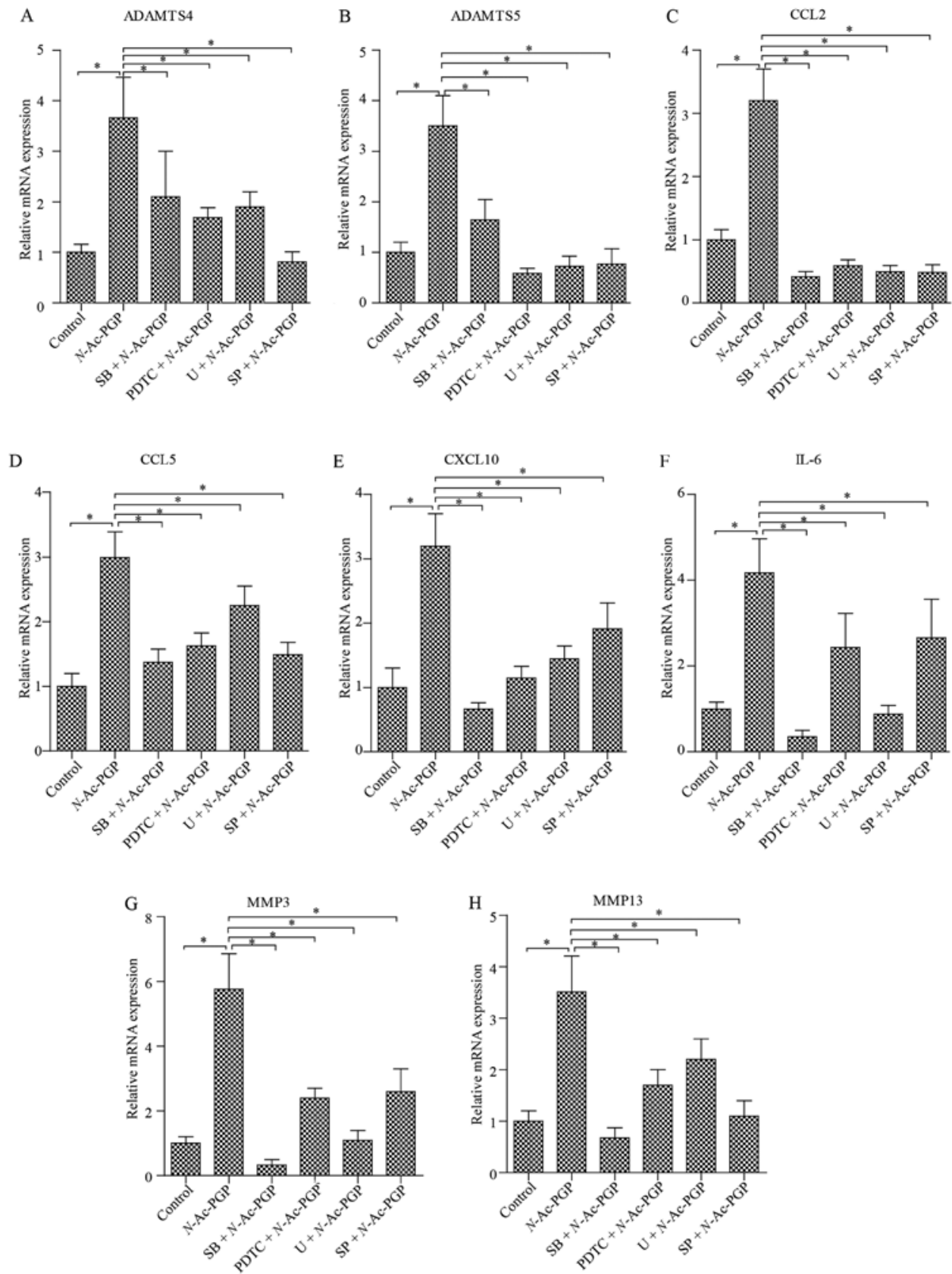

Figure 6. (A-H) Quantitative PCR analysis of matrix degradation enzymes and pro-inflammatory cytokines in NP cells treated with $N$-acetylated proline-glycine-pro-line ( $N$-Ac-PGP, $100 \mu \mathrm{g} / \mathrm{ml}$ ) for 3 days. NP cells were pretreated with p38 inhibitor (SB202190, SB), JNK inhibitor (SP600125, SP), ERK inhibitor (U0126, U) or nuclear factor- $\mathrm{kB}(\mathrm{NF}-\mathrm{kB})$ inhibitor (PDTC) for $30 \mathrm{~min}$ followed by $\mathrm{N}$-Ac-PGP treatment for signaling inhibition. The results are presented as the mean \pm SEM. " $\mathrm{P}<0.05$. NP, nucleus pulposus; ADAMTS, a disintegrin and metalloproteinase with thrombospondin motifs; CCL, C-C motif ligand; CXCL10, C-X-C motif chemokine ligand 10; IL, interleukin; MMP, matrix metalloproteinase.

cells in a dose-dependent manner. Herein, we investigated the relationship between the duration of $N$-Ac-PGP treatment and the pro-inflammatory effect of $N$-Ac-PGP on NP cells. We found that the level of pro-inflammatory cytokines in culture media significantly increased after $N$-Ac-PGP treatment (100 $\mu \mathrm{g} / \mathrm{ml}$ ) for 1 day (Fig. 5). With the prolonged duration of $N$-Ac-PGP treatment, the production of cytokines by NP cells was gradually increased (Fig. 5), indicating that $N$-Ac-PGP induces the secretion of pro-inflammatory cytokines by NP cells in a time-dependent manner.

$N$-Ac-PGP upregulates the expression of matrix degradation proteases in NP cells. In addition to the pro-inflammatory phenotype, the matrix catabolic phenotype of NP cells is a main threat to the ECM homeostasis of discs and is crucial to the pathogenesis of IDD. However, the influence of $N$-Ac-PGP on the expression of matrix catabolic genes in human NP cells is unknown. To elucidate this issue, NP cells were incubated with $N$-Ac-PGP $(100 \mu \mathrm{g} / \mathrm{ml})$ for 3 days. RT-qPCR analysis was then performed to detect the expression of various matrix degradation proteases in the NP cells, including MMP3, MMP13, a disintegrin and metalloproteinase with thrombospondin motif 4 (ADAMTS4) and ADAMTS5 (Fig. 6). As a result, the expression of matrix proteases was markedly upregulated by $N$-Ac-PGP. In contrast, a significant upregulation of IL-6, CCL2, CCL5 and C-X-C motif ligand 10 (CXCL10) in NP cells 
A

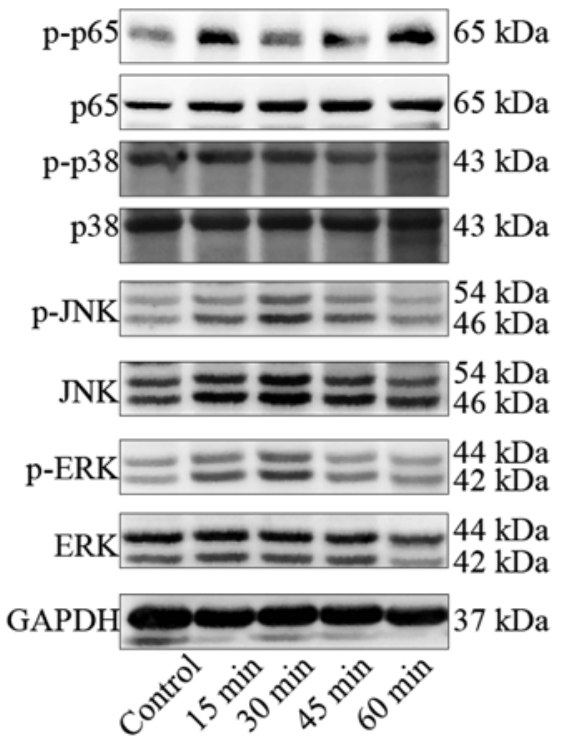

B
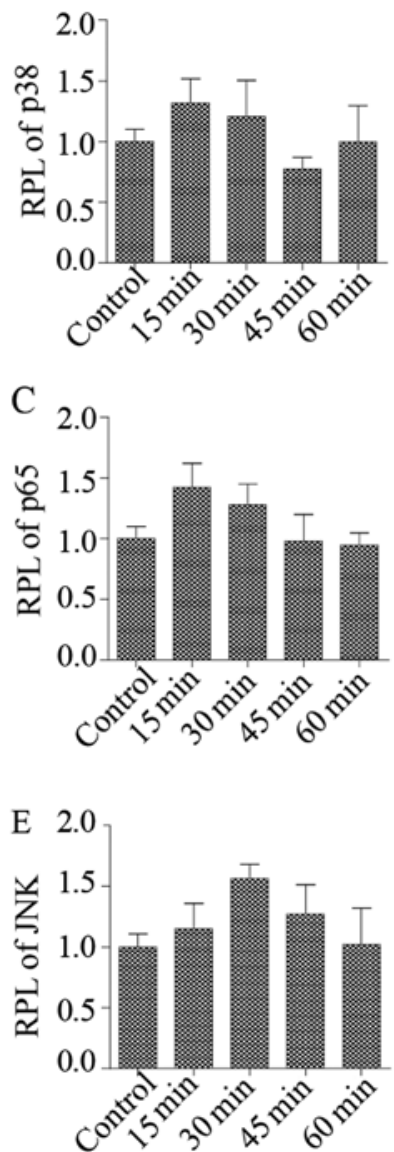

Figure 7. (A) Western blot analysis of the phosphorylation of p38, ERK, JNK and p65 in nucleus pulposus (NP) cells treated with $N$-acetylated proline-glycine-proline ( $N$-Ac-PGP, $100 \mu \mathrm{g} / \mathrm{ml}$ ) for 15, 30, 45 and $60 \mathrm{~min}$. (B-E) The relative phosphorylation level (RPL) of p38, p65, ERK, JNK in NP cells treated with $N$-Ac-PGP. NP cells without any treatment served as the control.

was also induced by $N$-Ac-PGP (Fig. 6), which was consistent with the results of the Milliplex MAP assays. In conclusion, $\mathrm{N}$-Ac-PGP is able to regulate both inflammatory and catabolic signaling in NP cells, confirming the pro-inflammatory and catabolic effect of $N$-Ac-PGP in the microenvironment of discs.

$N F-\kappa B$ and MAPK signaling pathways are involved in the pro-inflammatory and catabolic effect of $N$-Ac-PGP on $N P$ cells. NF- $\kappa \mathrm{B}$ and MAPK signaling pathways are crucial to the regulation of inflammatory and catabolic signaling in IVDs (20). To investigate whether $N$-Ac-PGP regulates the pro-inflammatory and matrix catabolic phenotype of NP cells through $\mathrm{NF}-\kappa \mathrm{B}$ and MAPK pathways, the phosphorylation of ERK, JNK, p38 and p65 in NP cells treated with $N$-Ac-PGP $(100 \mu \mathrm{g} / \mathrm{ml})$ was analyzed. Two signaling pathways of MAPK (ERK and JNK) were maximally phosphorylated after $N$-Ac-PGP treatment for 30 min while p38 and p65 were maximally phosphorylated after $N$-Ac-PGP treatment for $15 \mathrm{~min}$ (Fig. 7). After $N$-Ac-PGP treatment for 15 or $30 \mathrm{~min}$, the phosphorylation levels of ERK, JNK, p38 and p65 were gradually decreased and returned to normal (Fig. 7), indicating that the NF- $\mathrm{\kappa F}$ and MAPK signaling pathways in NP cells were activated at the early stage of $N$-Ac-PGP treatment. In order to investigate the efficacy of the specific signaling inhibitors on the phosphorylation of p65, ERK, JNK, p38 in NP cells at the early stage of $N$-Ac-PGP treatment, NP cells were pre-treated with $\mathrm{U}(1 \mu \mathrm{g} / \mathrm{ml}), \mathrm{SP}(1 \mu \mathrm{g} / \mathrm{ml}), \mathrm{SB}(1 \mu \mathrm{g} / \mathrm{ml})$ and PDTC $(1 \mu \mathrm{g} / \mathrm{ml})$ for $30 \mathrm{~min}$ followed by $N$-Ac-PGP treatment $(100 \mu \mathrm{g} / \mathrm{ml})$ for $30 \mathrm{~min}, 30 \mathrm{~min}, 15 \mathrm{~min}$ and $15 \mathrm{~min}$ respectively. As a result, the specific signaling inhibitors suppressed the phosphorylation of p65, ERK, JNK and p38 at the early stage of $N$-Ac-PGP treatment (Fig. 8). Furthermore, the results of RT-qPCR revealed that the inductive effect of $N$-Ac-PGP treatment for 3 days on the expression of CCL2, CCL5, IL-6, CXCL10, MMP3, MMP13, ADAMTS4 and ADAMTS5 in NP cells was retarded by the specific signaling inhibitors (Fig. 6), suggesting that the pro-inflammatory and matrix catabolic effect of $\mathrm{N}$-Ac-PGP on NP cells is mediated by the activation of $\mathrm{NF}-\kappa \mathrm{B}$ and MAPK signaling pathways at the early stage of $N$-Ac-PGP treatment.

\section{Discussion}

In the present study, we demonstrated that $N$-Ac-PGP induces the expression of pro-inflammatory cytokines and ECM proteases in human NP cells, which was consistent with the pro-inflammatory and catabolic effect of $N$-Ac-PGP on human CESCs (15). This suggests that $N$-Ac-PGP is involved in the pathogenesis of IDD by enhancing inflammation and promoting 
A
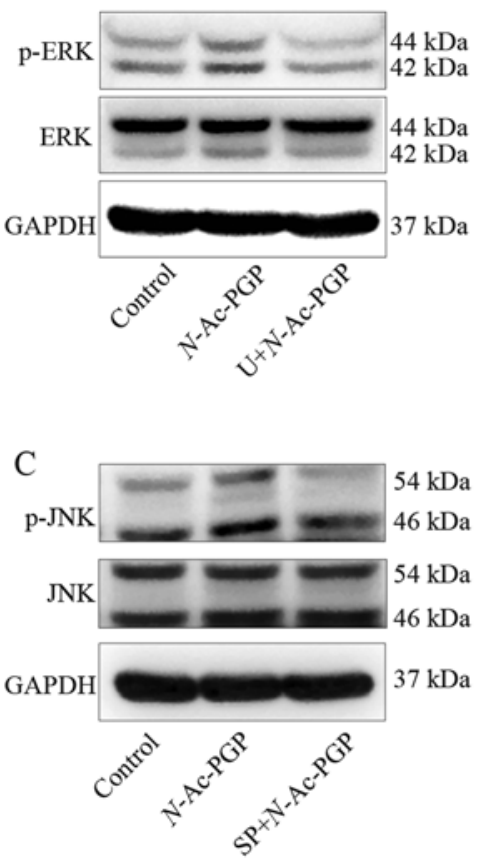

B
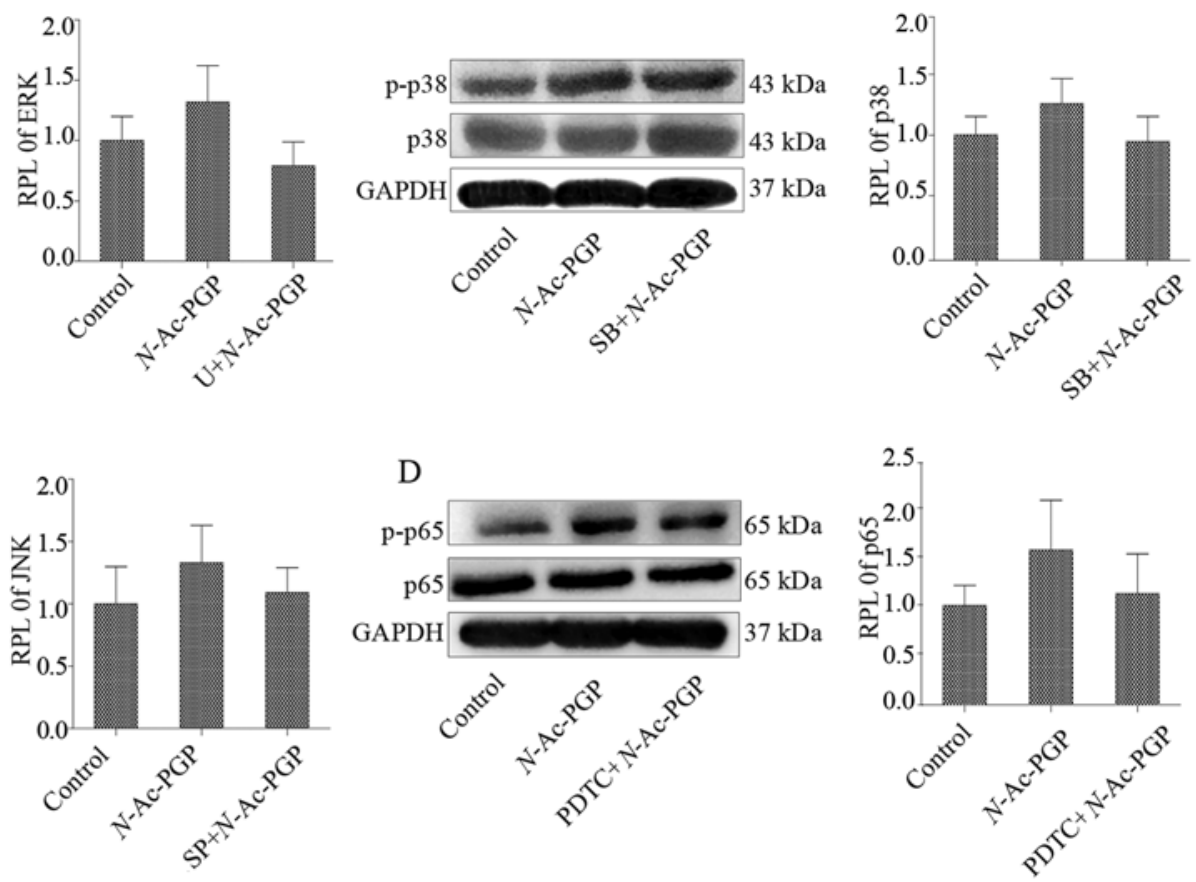

Figure 8. (A-D) Western blot analysis of the phosphorylation of ERK, p38, JNK and p65 in nucleus pulposus (NP) cells. NP cells were pre-treated with the ERK (U0126, U, $1 \mu \mathrm{g} / \mathrm{ml}$ ), JNK (SP600125, SP, $1 \mu \mathrm{g} / \mathrm{ml}$ ), p38 (SB202190, SB, $1 \mu \mathrm{g} / \mathrm{ml}$ ) and nuclear factor- $\mathrm{KB}$ (NF- $\mathrm{kB}$ ) (PDTC, $1 \mu \mathrm{g} / \mathrm{ml}$ ) signaling inhibitors for $30 \mathrm{~min}$ followed by $N$-acetylated proline-glycine-proline ( $N$-Ac-PGP) treatment $(100 \mu \mathrm{g} / \mathrm{ml})$ for 30, 30, 15 and 15 min respectively. The relative phosphorylation level (RPL) of p38, p65, ERK, JNK in NP cells was calculated. NP cells without any treatment served as the control.

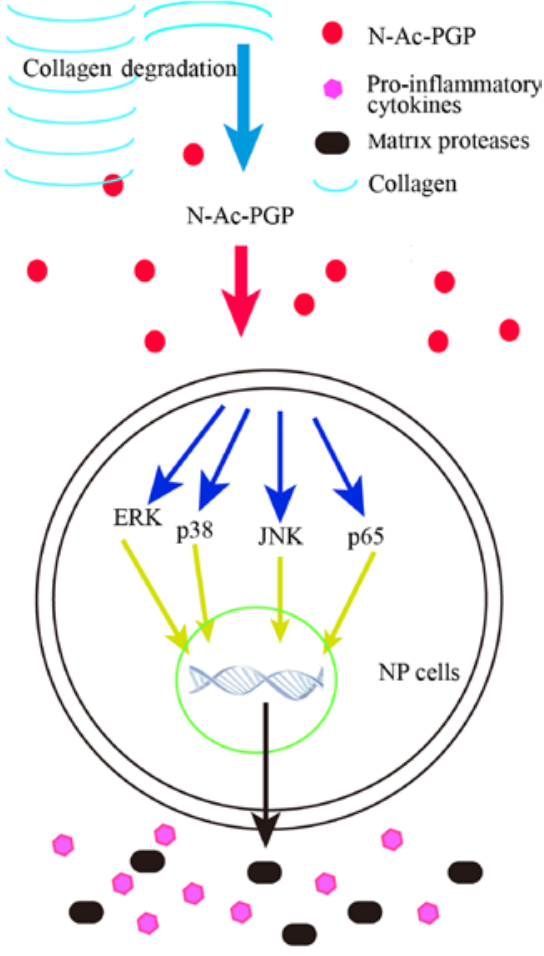

Figure 9. The schema of the signaling pathways investigated in this study. $\mathrm{N}$-acetylated proline-glycine-proline ( $N$-Ac-PGP) upregulates the expression of matrix catabolic and pro-inflammatory genes in nucleus pulposus (NP) cells via the activation of nuclear factor- $\mathrm{KB}(\mathrm{NF}-\mathrm{\kappa B})$ and mitogen-activated protein kinase (MAPK) signaling pathways.

ECM degradation in the microenvironment of IVDs. $N$-Ac-PGP is detrimental to the structural and functional homeostasis of
IVDs. Furthermore, the NF- $\mathrm{kB}$ and MAPK signaling pathways were shown to mediate the catabolic and pro-inflammatory effect of $N$-Ac-PGP on NP cells. To our knowledge, this is the first study to investigate the effect of $N$-Ac-PGP on the phenotype of human NP cells and the molecular pathways underlying this effect, which provides further insight into the pathogenesis of IDD.

The structural and functional maintenance of IVDs depends on a balance between the ECM anabolism and catabolism of disc cells $(21,22)$. This balance is disturbed in degenerative discs. Various matrix catabolic proteases accumulate in the microenvironment of discs with IDD progression, including MMP3, MMP13, ADAMTS4 and ADAMTS5. These proteases degrade ECM to cause structural failure of IVDs (9). On the other hand, IDD is a pro-inflammatory cytokine-mediated pathological process. Various pro-inflammatory cytokines including TNF- $\alpha$, IL-6, IL-17, IL-1 $\beta$ and CCL2 produced by disc cells upregulate the expression of matrix proteases and suppress matrix anabolism in disc cells via autocrine and paracrine processes. Moreover, pro-inflammatory mediators induce the senescence, autophagy and apoptosis of disc cells $(10,23)$. In short, pro-inflammatory cytokines and matrix proteases are crucial to the establishment and progression of IDD. Therefore, the matrix catabolic and pro-inflammatory secretory phenotype of disc cells plays an important role in the pathogenesis of IDD. Noticeably, the phenotype of resident disc cells is regulable for the adaption to the microenvironment of IDD. In addition, the function and viability of disc cells depend on microenvironment homeostasis. The microenvironment of degenerative discs is harsh and is characterized by an acidic $\mathrm{pH}$, high osmotic pressure, low oxygen and nutrition 
deficiency. With IDD progression, the microenvironment of discs becomes harsher due to excessive cytokines, chemokines, proteases and growth factors $(11,24)$. Investigation of the effects of microenvironmental factors on the matrix catabolic and pro-inflammatory phenotype of disc cells facilitates the development of strategies to suppress the production of cytokines and matrix proteases by disc cells and consequently prevents or delays the establishment and progression of IDD.

$\mathrm{N}$-Ac-PGP is a matrikine derived from collagen through a proteolytic cascade involving MMP8, MMP9 and PE (12). It is a chemokine via CXCR1/2 (25). Previous studies have reported the involvement of $\mathrm{N}$-Ac-PGP in chronic obstructive pulmonary disease and inflammatory bowel disease via inducing the migration of neutrophils $(13,14)$. We reported that the levels of MMP8, MMP9 and PE in human NP tissues were significantly increased with increasing Pfirrmann grade of the discs, suggesting an enhanced collagen degradation in degenerative discs that forms a suitable microenvironment for $N$-Ac-PGP generation. In fact, we confirmed the presence of $N$-Ac-PGP in human NP tissues and found that the level of $N$-Ac-PGP in NP tissues is positively correlated with the Pfirrmann grade of IVDs. Furthermore, $N$-Ac-PGP was shown to recruit CESCs from cartilage endplate into NP and induce the differentiation of CESCs toward a pro-inflammatory phenotype (15). Herein, the roles of $N$-Ac-PGP in the microenvironment of NP were extended. $N$-Ac-PGP potently induced the expression of matrix catabolic and pro-inflammatory genes in resident NP cells, suggesting that $N$-Ac-PGP is detrimental to the functional and structural homeostasis of IVDs via enhancing inflammation and matrix catabolism in the microenvironment of discs. $N$-Ac-PGP is a pro-degenerative matrikine for IVDs.

The NF- $\kappa \mathrm{B}$ and MAPK signaling pathways are regarded as the major pathways mediating musculoskeletal disorders, including osteoarthritis, osteoporosis muscular dystrophy and rheumatoid arthritis (26-31). NF- $\mathrm{BB}$ plays a central role in the cellular response to various stimuli, such as inflammation, cytokines, mechanical stress, oxidative stress and genotoxic stress. Previous studies have reported the roles of $\mathrm{NF}-\kappa \mathrm{B}$ in IDD. Nerlich et al reported the activation of NF- $\kappa \mathrm{B}$ along with oxidative stress in human IVDs in vivo. The activity of $\mathrm{NF}-\kappa \mathrm{B}$ in IVDs was found to increase with aging and progression of IDD (32). NF- $\mathrm{B}$ activation is associated with oxidative stress-induced senescence of NP cells (33). Moreover, MMPs, ADAMTS proteases and cytokines are the target genes of $\mathrm{NF}-\kappa \mathrm{B}$ in NP cells $(20,34,35)$, indicating that the $\mathrm{NF}-\kappa \mathrm{B}$ pathway is involved in the matrix catabolism and inflammation of IVDs. On the other hand, MAPK is a highly conserved signal transduction pathway that is activated by environmental stress (36). The ECM metabolism and inflammation of IVDs are also associated with MAPK activation in disc cells. The inhibition of the MAPK pathway by specific signaling inhibitors can suppress the enhanced ECM catabolism in disc cells induced by inflammatory cytokines (20,37-39). In conclusion, both $\mathrm{NF}-\kappa \mathrm{B}$ and MAPK pathways are tightly associated with inflammatory and matrix catabolic signaling in IVDs. Therefore, we propose that they also play a role in mediating the pro-inflammatory and catabolic effect of $N$-Ac-PGP on NP cells. According to our results, the phosphorylation of the $\mathrm{NF}-\kappa \mathrm{B}$ and MAPK pathways in NP cells was enhanced at the early stage of $N$-Ac-PGP treatment. Moreover, when the activation of NF- $\kappa \mathrm{B}$ and MAPK pathways at the early stage of $N$-Ac-PGP treatment was inhibited by specific signaling inhibitors, the pro-inflammatory and catabolic effects of $N$-Ac-PGP on NP cells was markedly counteracted, suggesting that $N$-Ac-PGP upregulates the expression of matrix catabolic and pro-inflammatory genes in NP cells via the activation of the NF- $\kappa \mathrm{B}$ and MAPK signaling pathways at the early stage of $N$-Ac-PGP treatment (Fig. 9).

Actually, there are several limitations of this study. Firstly, the mechanism underlying the interaction between $N$-Ac-PGP and NP cells remains unknown. Our previous study revealed that $N$-Ac-PGP affects CESCs by binding to $N$-Ac-PGP receptors (CXCR1 and CXCR2) (15). More studies are required to confirm that the effect of $N$-Ac-PGP on NP cells is also dependent on these receptors. Second, our study clearly showed that $N$-Ac-PGP affects NP cells via the NF- $\kappa$ B and MAPK signaling pathways. However, the crosstalk between the two pathways is unclear. This is a new issue which warrants further investigation. In addition, we pooled NP cells from different patients at passage 1 and used them at passage 2 or 3 . In this situation, the effect of different degeneration grade on the response of NP cells to $N$-Ac-PGP treatment was unable to be revealed. This should be investigated in the future.

In conclusion, $N$-Ac-PGP upregulates the expression of pro-inflammatory and ECM catabolic genes in a dose-dependent and time-dependent manner. This effect was mediated by the activation of the NF- $\kappa \mathrm{B}$ and MAPK signaling pathways at the early stage of $N$-Ac-PGP treatment. Our findings contribute to a better understanding of the roles of $N$-Ac-PGP in the pathogenesis of IDD and facilitates the development of a novel therapeutic approach targeting $N$-Ac-PGP to prevent or retard the initiation and progression of IDD.

\section{References}

1. Roberts S, Evans H, Trivedi J and Menage J: Histology and pathology of the human intervertebral disc. J Bone Joint Surg Am 88 (Suppl 2): 10-14, 2006.

2. Battié MC, Videman T, Kaprio J, Gibbons LE, Gill K, Manninen H, Saarela $J$ and Peltonen L: The twin spine study: contributions to a changing view of disc degeneration. Spine J 9: 47-59, 2009.

3. Xing QJ, Liang QQ, Bian Q, Ding DF, Cui XJ, Shi Q and Wang YJ: Leg amputation accelerates senescence of rat lumbar intervertebral discs. Spine 35: E1253-E1261, 2010.

4. Wang D, Nasto LA, Roughley P, Leme AS, Houghton AM, Usas A, Sowa G, Lee J, Niedernhofer L, Shapiro S, et al: Spine degeneration in a murine model of chronic human tobacco smokers. Osteoarthritis Cartilage 20: 896-905, 2012.

5. Stirling A, Worthington T, Rafiq M, Lambert PA and Elliott TS: Association between sciatica and Propionibacterium acnes. Lancet 357: 2024-2025, 2001.

6. Park EY and Park JB: Dose- and time-dependent effect of high glucose concentration on viability of notochordal cells and expression of matrix degrading and fibrotic enzymes. Int Orthop 37: 1179-1186, 2013.

7. Adams MA and Roughley PJ: What is intervertebral disc degeneration, and what causes it? Spine 31: 2151-2161, 2006.

8. Binch AL, Cole AA, Breakwell LM, Michael AL, Chiverton N, Creemers LB, Cross AK and Le Maitre CL: Nerves are more abundant than blood vessels in the degenerate human intervertebral disc. Arthritis Res Ther 17: 370, 2015.

9. Vo NV, Hartman RA, Yurube T, Jacobs LJ, Sowa GA and Kang JD: Expression and regulation of metalloproteinases and their inhibitors in intervertebral disc aging and degeneration. Spine J 13: 331-341, 2013.

10. Risbud MV and Shapiro IM: Role of cytokines in intervertebral disc degeneration: pain and disc content. Nat Rev Rheumatol 10: 44-56, 2014. 
11. Huang YC, Leung VY, Lu WW and Luk KD: The effects of microenvironment in mesenchymal stem cell-based regeneration of intervertebral disc. Spine J 13: 352-362, 2013.

12. Gaggar A, Jackson PL, Noerager BD, O'Reilly PJ, McQuaid DB, Rowe SM, Clancy JP and Blalock JE: A novel proteolytic cascade generates an extracellular matrix-derived chemoattractant in chronic neutrophilic inflammation. J Immunol 180: 5662-5669, 2008.

13. O'Reilly P, Jackson PL, Noerager B, Parker S, Dransfield M, Gaggar A and Blalock JE: N-alpha-PGP and PGP, potential biomarkers and therapeutic targets for COPD. Respir Res 10: $38,2009$.

14. Koelink PJ, Overbeek SA, Braber S, Morgan ME, Henricks PA, Abdul Roda M, Verspaget HW, Wolfkamp SC, te Velde AA, Jones CW, et al: Collagen degradation and neutrophilic infiltration: a vicious circle in inflammatory bowel disease. Gut 63: $578-587,2014$.

15. Feng $C$, Zhang $Y$, Yang $M$, Huang $B$ and Zhou $Y$ : Collagen-derived $\mathrm{N}$-acetylated proline-glycine-proline in intervertebral discs modulates CXCR $1 / 2$ expression and activation in cartilage endplate stem cells to induce migration and differentiation toward a pro-inflammatory phenotype. Stem Cells 33: 3558-3568, 2015

16. Pfirrmann CW, Metzdorf A, Zanetti M, Hodler J and Boos N: Magnetic resonance classification of lumbar intervertebral disc degeneration. Spine 26: 1873-1878, 2001.

17. Lv F, Leung VY, Huang S, Huang Y, Sun Y and Cheung KM: In search of nucleus pulposus-specific molecular markers. Rheumatology (Oxford) 53: 600-610, 2014.

18. Livak KJ and Schmittgen TD: Analysis of relative gene expression data using real-time quantitative PCR and the 2(-Delta Delta C(T)) method. Methods 25: 402-408, 2001.

19. Hiyama A, Sakai D, Risbud MV, Tanaka M, Arai F, Abe K and Mochida J: Enhancement of intervertebral disc cell senescence by $\mathrm{WNT} / \beta$-catenin signaling-induced matrix metalloproteinase expression. Arthritis Rheum 62: 3036-3047, 2010.

20. Wuertz K, Vo N, Kletsas D and Boos N: Inflammatory and catabolic signalling in intervertebral discs: the roles of $\mathrm{NF}-\kappa \mathrm{B}$ and MAP kinases. Eur Cell Mater 23: 103-119, 2012.

21. Feng C, Liu H, Yang Y, Huang B and Zhou Y: Growth and differentiation factor-5 contributes to the structural and functional maintenance of the intervertebral disc. Cell Physiol Biochem 35: $1-16,2015$.

22. Kepler CK, Ponnappan RK, Tannoury CA, Risbud MV and Anderson DG: The molecular basis of intervertebral disc degeneration. Spine J 13: 318-330, 2013.

23. Ding F, Shao ZW and Xiong LM: Cell death in intervertebral disc degeneration. Apoptosis 18: 777-785, 2013.

24. Huang YC, Urban JP and Luk KD: Intervertebral disc regeneration: do nutrients lead the way? Nat Rev Rheumatol 10 561-566, 2014.

25. Weathington NM, van Houwelingen AH, Noerager BD, Jackson PL, Kraneveld AD, Galin FS, Folkerts G, Nijkamp FP and Blalock JE: A novel peptide CXCR ligand derived from extracellular matrix degradation during airway inflammation. Nat Med 12: 317-323, 2006

26. Marcu KB, Otero M, Olivotto E, Borzi RM and Goldring MB: NF-kappaB signaling: multiple angles to target OA. Curr Drug Targets 11: 599-613, 2010.
27. Kim HJ, Chang EJ, Kim HM, Lee SB, Kim HD, Su Kim G and Kim HH: Antioxidant alpha-lipoic acid inhibits osteoclast differentiation by reducing nuclear factor-kappaB DNA binding and prevents in vivo bone resorption induced by receptor activator of nuclear factor-kappaB ligand and tumor necrosis factor-alpha. Free Radic Biol Med 40: 1483-1493, 2006.

28. Acharyya S, Villalta SA, Bakkar N, Bupha-Intr T, Janssen PM, Carathers M, Li ZW, Beg AA, Ghosh S, Sahenk Z, et al: Interplay of IKK/NF-kappaB signaling in macrophages and myofibers promotes muscle degeneration in Duchenne muscular dystrophy. J Clin Invest 117: 889-901, 2007.

29. Dai S, Hirayama T, Abbas S and Abu-Amer Y: The IkappaB kinase (IKK) inhibitor, NEMO-binding domain peptide, blocks osteoclastogenesis and bone erosion in inflammatory arthritis. J Biol Chem 279: 37219-37222, 2004.

30. Huang P, Han J and Hui L: MAPK signaling in inflammation-associated cancer development. Protein Cell 1: 218-226, 2010.

31. Zarubin $\mathrm{T}$ and Han J: Activation and signaling of the p38 MAP kinase pathway. Cell Res 15: 11-18, 2005.

32. Nerlich AG, Bachmeier BE, Schleicher E, Rohrbach H, Paesold $G$ and Boos N: Immunomorphological analysis of RAGE receptor expression and NF-kappaB activation in tissue samples from normal and degenerated intervertebral discs of various ages. Ann NY Acad Sci 1096: 239-248, 2007.

33. Dimozi A, Mavrogonatou E, Sklirou A and Kletsas D: Oxidative stress inhibits the proliferation, induces premature senescence and promotes a catabolic phenotype in human nucleus pulposus intervertebral disc cells. Eur Cell Mater 30: 89-102, 2015.

34. Séguin CA, Bojarski M, Pilliar RM, Roughley PJ and Kandel RA: Differential regulation of matrix degrading enzymes in a TNFalpha-induced model of nucleus pulposus tissue degeneration. Matrix Biol 25: 409-418, 2006.

35. Wako M, Ohba T, Ando T, Arai Y, Koyama K, Hamada Y, Nakao A and Haro H: Mechanism of signal transduction in tumor necrosis factor-like weak inducer of apoptosis-induced matrix degradation by MMP-3 upregulation in disc tissues. Spine 33: 2489-2494, 2008.

36. Kyriakis JM and Avruch J: Mammalian mitogen-activated protein kinase signal transduction pathways activated by stress and inflammation. Physiol Rev 81: 807-869, 2001.

37. Kim JS, Ellman MB, An HS, Yan D, van Wijnen AJ, Murphy G, Hoskin DW and Im HJ: Lactoferricin mediates anabolic and anti-catabolic effects in the intervertebral disc. J Cell Physiol 227: 1512-1520, 2012

38. Kim JH, Studer RK, Vo NV, Sowa GA and Kang JD: p38 MAPK inhibition selectively mitigates inflammatory mediators and VEGF production in AF cells co-cultured with activated macrophage-like THP-1 cells. Osteoarthritis and cartilage/OARS Osteoarthritis Res Soc 17: 1662-1669, 2009.

39. Séguin CA, Pilliar RM, Madri JA and Kandel RA: TNF-alpha induces MMP2 gelatinase activity and MT1-MMP expression in an in vitro model of nucleus pulposus tissue degeneration. Spine 33: 356-365, 2008. 